\title{
Las relaciones internacionales y la diplomacia en el conflicto armado
}

\section{I. ¿ Se ganan las guerras en el extranjero ?}

Hasta la fecha ninguna guerra revolucionaria ha sido ganada en el extranjero; las guerras de liberación triunfan en los países en contienda militar y no en el exterior. Sin embargo el apoyo diplomático es algunas veces un factor importante para ponerle coto al enfrentamiento armado. Esto no quiere decir que no existe guerra diplomática como una prolongación del conflicto interno. En este caso, se hablará más bien de una batalla diplomática donde las partes se enfrentan en la escena internacional, para ganar un combate, cuyo triunfo dependerá del aislamiento de una de las partes contendientes.

La lucha diplomática es factible que la gane la guerrilla cuando ésta sepa aprovechar la contradicción del gobierno oficial en cuanto a la política interna y externa, puesto que por regla general, su política doméstica se enmarcará dentro del terrorismo institucionalizado, y su política internacional pretenderá hacerla aparecer ante el mundo como respetuosa de los derechos humanos. El gobierno trata de engañar a la comunidad internacional al hacer creer que su política exterior es el reflejo de su política interna. "Se puede por otro lado relevar que, en numerosos países, notablemente en el Tercer Mundo, la política extranjera es a menudo utilizada como un instrumento priviligiado de ligitimación de regímenes de turno"'.

Es un error ceer que las revoluciones se ganan en el extranjero por el hecho, de que varias de esta guerras de liberación se hayan terminado por la vía de negociaciones. Algunos de estos casos han sido guerras anti-coloniales y antiimperialistas, como por ejemplo: Viet-Nam, Libia, y Namibia. La negociación se ha efectuado también en las guerras de liberación nacional donde el enemigo es un país intervencionista.

Una guerra anticolonial se termina por lo general, cuando el enemigo sale del país intervenido, y en el momento que a sus acólitos se les despoja de los privile- 
gios concedidos por la metrópoli. Una guerra convencional se puede terminar según los procedimientos del derecho de la guerra o del internacional público, por ejemplo: rendición, armisticio, arreglo pacífico de la controversia, ya sea por, la negociación, la investigación, la mediación, la conciliación, el arbitraje, el arreglo judicial, el recurso a organismos o acuerdos regionales u otros medios pacíficos de su elección ${ }^{2}$. Notemos los ejemplos de Alemania y del Japón en la Segunda Guerra Mundial; los de Irán y de Irak en la guerra del Golfo Pérsico.

La negociación diplomática entre las partes en conflicto sea, bilateral (Marruecos-Sahara Occidental), multilateral (Angola-Sudáfrica-Cuba), o internacional (Kampuchea) obedece fundamentalmente a la voluntad de las partes beligerantes de poner fin al conflicto.

En los casos de la revolución cubana y sandinista, no hubo negociaciones para poner término a la lid revolucionaria. La diplomacia en ambos conflictos anteriores no jugó un rol determinante como lo fue en la guerra de Algeria contra el imperialismo francés.

En una revolución, el enemigo está al interior del país y se le debe poner fuera de combate en el campo político-militar propiamente dicho.

Los regímenes reaccionarios son por regla general sotenidos por los EE.UU., y en estas circunstancias agravantes, las guerras revolucionarias no son literalmente nacionales, porque intervine un país extranjero, que se convierte logicamente en parte del conflicto, puesto que él asiste militar, económica y diplomáticamente al enemigo. Fue el caso de los contras nicaraguenses y en El Salvador con los gobiemos del Partido Demócrata Cristiano (PDC) y del Partido Alianza Republicana Nacionalista (ARENA).

En Nicaragua, la negociaciones con el enemigo se hicieron indirectamente por medio de sus bandas armadas, es decir con la "contra". El enemigo principal del gobierno sandinista fueron siempre los EE.UU., puesto que éstos avituallaban a los "contras" con armas. Ellos dirigieron la guerra "no declarada" contra el pueblo y gobierno nicaraguense ${ }^{3}$. Los "contras" eran simples instrumentos que los EE.UU. utilizaron para degastar economicamente a los sandinistas, impidiendoles de esta forma poder continuar con la reconstrucción del país, a través de proyectos y, reformas en los diferentes campos de la sociedad, puesto que más del 50 por ciento del presupuesto nacional se utilizaba en la rama militar para poder defenderese del imperialismo.

Los EE.UU., posteriormente auxiliaron a las bandas de la "contra" fundamentalmente con dólares, este sostén millonario sirvió para financiar el partido político de la contra, para que presentara como candidato presidencial a Violeta Chamarro, quien se convirtió ipso facto en el partido político que representaría los intereses geo-políticos y geo-estratégicos de los EE.UU. no sólo en Nicaragua, sino en todo el istmo centroaméricano. 
El Salvador, no fue completamente distinto del ejemplo de Nicaragua, la diferencia radicó en que los "contras" de El Salvador no estuvieron en Honduras ni tampoco en Costa Rica; ellos estaban en el poder desde la "independencia patria" (1821).

En los conflictos regionales y, principalmente en las guerras de liberación, la diplomacia juega un rol importante, con la participación de los diferentes actores internacionales que intervienen, con el fin, de evitar una internacionalización del conflicto, puesto que esta situación podría justamente poner en peligro la paz y la seguridad internacional.

La diplomacia del movimiento revolucionario, se desarrolla y llega a un punto de eficacia cuando ésta alcanza un grado de desarrollo significativo, y representa una parte importante de la población, en estas condiciones se le hace difícil al enemigo de situarla como una banda de terroristas aislada completamente de la población, también cuando parece evidente a la comunidad internacional que el gobierno de turno no es representativo ni mucho menos popular.

Sin embargo, no quiere decir quel imperialismo y sus sicarios, no intentarán otros subterfugios para desprestigiar a los movimientos revolucionarios, por ejemplo, los EE.UU. relacionan a las guerrillas con los narcotraficantes, al mismo tiempo que ellos mismos crean bandas armadas tipos "contras" nicaraguenses, quienes se dedicaban a practicar el terrorismo y a vivir de los dólares de la CIA y del nacotráfico. Por otra parte, escritores extranjeros, "especialistas" en América Latina, como los franceses Jacques Lambert y Gandolfi, afirman que: "La guerrilla adquiere así un tal prestigio porque ella sirve de covertura a vulgares organizaciones de droga"4.

Las guerras de liberación no pueden ser consideradas más como enfrentamientos entre el Este y el Oeste. La etapa histórica de la bipolaridad y la guerra fría desapareció, las relaciones internacionales han pasado del enfrentamiento a la cooperación internacionals. "Aunque la distensión (entente) Estados Unidos-URSS se desarrolló en detrimento de terceros (véase Nicaragua, Panamá, etc.).

Los movimientos revolucionarios, de guatemala, El Salvador y de otros países de América Latina no fueron el resultado del enfrentamiento Este-Oeste, sino un resultado del enfrentamiento Norte-Sur y, sobre todo como consecuencia de condiciones históricas y estructurales..

Las luchas revolucionarias la circunscribían en el contexto bipolar porque los países donde existían las guerrillas pertenecían por lo general a la zona de influencia o de seguridad de una de las dos superpotencias (URSS-EE.UU.). Veamos como la comunidad internacional empezó a cambiar: mientras los soviéticos permitieron los cambios políticos y económicos en Polonia, Checoslovaquia, Rumania, Bulgaria, etc, es decir, no sólo en su esfera de influencia, en su zona de seguridad sino que además fueron aliados militares y económicos pertenecientes al 
Pacto de Varsovia y al COMECON respectivamente; mientras esto acontecía los EE.UU. proseguían enviando dólares y armas a la "contra" nicaraguense, enviando alrededor de un millón y medio de dólares diarios al gobiemo y Fuerza Armada "Salvadoreña" para continuar reprimiendo y asesinando a la sociedad civil, en esta misma coyuntura de detente internacional los EE.UU. invadieron militarmente a Panamá.

Fue necesario para mayor comprensión y mejores resultados de la acción diplomática del movimiento revolucionario, que se explicara a los diferentes actores internacionales las causas del conflicto y, sus objetivos revolucionarios y dejar en claro que no fue una lucha entre el Este y el Oeste, como los EE.UU. pretendían hacerlo creer a la comunidad internacional, para legitimar su intervención en los conflictos internos de los países convulsionados.

Lo que significaba que sólo había cambiado una faz de la comunidad internacional, porque por lo que respeta a los EE.UU., ellos prosiguían a ultranza con su política intervencionista e imperialista.

\section{Estrategias empleadas para ganar el apoyo político y diplomático}

Antes de definir las estrategias empleadas para ganar el sostén político y diplomático, es menester explicar que para garantizar la eficacidad de las mismas, fue indispensable tener una infraestructura apropiada.

El movimiento revolucionario, debía tener o estar representado por un comité, un ejecutivo, un departamento o una comisión (no importa la denominación) polftico-diplomática que catalizará las relaciones internacionales, a los diferentes niveles con las organizaciones humanitarias, sindicatos, partidos políticos, instituciones, gobiernos, etc.

El comité político-diplomático (se le llamará únicamente comité), comprendía una estructura orgánica y funcional, donde se encuentraban no solamente los secretarios o responsables de las relaciones internacionales de las diferentes organizaciones que componían el frente revolucionario, sino que también fue estrictamente necesaria la presencia de: intelectuales, obreros, estudiantes, etc. La estructura del comité era edificada de tal suerte que respetara el pricipio de síntesis de la autonomía y de la coordinación. La estructura facilitaba las comunicaciones y la división de las funciones?.

Fue imprescindible que existiera en la organización del comité una representatividad ideológica. Se habla de reprentatividad ideológica cuando la vanguardia revolucionaria está constituida por las diferentes fuerzas vivas del país (comunistas, social-demócratas, cristianos, etc.), que luchaban contra un gobierno reaccionario y en contra del imperialismo. 
Obviamente, el comité comtemplaba un organigrama, en dode se establecían divisiones precisas de trabajo, no sólo de orden geográfico e ideológico, sino que también de diferentes niveles en las relaciones intemacionales con las instituciones, organizaciones, partidos políticos, etc, de no haber existido una centralización de estas funciones, se hubiera dado paso a la anarquía y negligentemente se hubiera fomentado el oportunismo y la comupción a todo nivel, puesto que las relaciones diplomáticas no se refirirfan estrictamente sólo a la cuestión política, sino que además, en muchos casos se relacionaban con el aspecto pecuniario.

El comité, nombraba a los representantes del movimiento revolucionario en los países designados, quienes tenían funciones similares a las que ejercían en la práctica los Embajadores, con el agravante que éstos representantes revolucionarios eran "hombres orquestas" en el extranjero, puesto que realizaban diversas funciones, que se relacionaban o contribuían a mejor ejercer sus tareas, ya que éstos a diferencia de los Embajadores, no tenían agregados, secretarios, ni personal doméstico, tampoco los estipendios eran elevados, más bien de subsistencia, justo para vivir y combatir eficazmente al enemigo en las "trincheras diplomáticas".

El comité cumplía sus funciones en relación con las necesidades de la revolución y de la estrategia general, las cuales, estaban contempladas en un programa que el comité elaboraba, a la vez estaba sujeto a los cambios coyunturales, a las revisiones y evaluaciones periódicas.

Los diversos representates del movimiento revolucionario acreditados en los diversos países, sometían un plan o programa al comité de las actividades que realizaría cada uno, y sería acorde al plan general del comité, para evitar: desviaciones, aventurerismo, improvisaciones innecesarias, oportunismo, corrupción, etc. Asimismo, los representantes entregarían períbdicamente un informe o balance de sus actividades. Esto no quiere decir que los representantes del movimiento revolucionario no gozaban de cierta y mesurada libertad discrecional. A título, de ejemplo, podemos mencionar las funciones siguientes:
A- Relaciones políticas
B- Solidaridad
C- Propaganda
D- Cooperación

\section{A- Relaciones políticas}

Se establecía relaciones con organizaciones, personalidades, instituciones y partidos políticos, entre otros, con el fin de establecer y mantener contactos. Estos se empleaban logicamente en favor de la causa revolucionaria, se aprovechaba la oportunidad de informarles de una manera directa los acontecimientos políticos y militares nacionales y, a la vez, para coordinar la realización de actividades solidarias, por ejemplo, seminarios, coloquios, mesas redondas y conferencias. 


\section{B- Solidaridad}

Esta función se dirigía a crear grupos de apoyo y a coordinar con los ya establecidos, actividades para promover la solidaridad entre los diferentes sectores y medios sociales y políticos del país anfitrión. Esto se haća en las universidades, en los sindicatos, etc, sobre todo, por ejemplo, organizar conciertos, bailes o manifestaciones frente a la Embajada del gobierno oficial o enfrente de la estadounidense.

\section{C- Propaganda}

Esta función tenía por objetivo elaborar, reproducir y distribuir los comunicados y, los órganos oficiales de divulgación del movimiento revolucianario, a los diferentes medios de prensa y propaganda de los partidos políticos, sindicatos, etc. La propaganda era en la medida de lo posible actualizada y distribuida puntualmente.

\section{D- Cooperación}

Esta función consistía en hacer gestiones o trámites para obtener asistencia económica para financiar fundamentalmente las actividades al interior del país y en segundo lugar las llevadas a cabo en el extranjero.

Existía una gama de organismos gubernamentales y no gubernamentales, que eran de carácter nacional, regional o internacional, igualmente, organizaciones o partidos políticos de diferentes posiciones ideológicas. Para cumplir esta función se tomaba en cuenta la ideología de la persona, por ejemplo, no se enviaba a un representante que tenía filiación comunista a gestionar ayuda financiera a una organización religiosa, tampocó a un socialdemocrata a gestionar asistencia económica a una organización de orientación troskista. El representante gestionaba ante el comité que se enviara a una persona idónea para hacer los trámites necesarios con el propósito de solicitar la cooperación, la cual podía ser continuada después, sin mayores riesgos por el representante acreditado en ese país.

La asistencia económica que se recibía el comité se enviaba a la respectiva secretaría de finanzas y auditoría (podía tener otra denominación), la cual se encargaba no sólo de hacerlo llegar por las vías establecidas al movimiento revolucionario, sino que también se encargaba de hacer inversiones, comprar acciones, depositarlo a plazos, montar proyectos productivos o de senvicios, etc, ya sea en el país donde se combatía o en el extrajero, para lo cual se creaba una asociación, compañía, empresa u otra similar, para darle cobertura a la secretaría de finanzas y auditoria del movimiento revolucionario, con el fin de reproducir y multiplicar el dinero, de esta manera se creaba una independencia y autonomía éconómica, a la vez política del movimiento revolucionario, de esta forma se evitaba de caer en la 
“MENDICIDAD, PORDIOSERIA Y EN EL PARASISTISMO INTERNACIONAL”.

En una guerra revolucionaria existen dos frentes: el militar y el polf́tico, este último comprende la diplomacia, en América Latina la diplomacia ocupó un rol importante en la década de los ochenta, aparecieron nuevos actores regionales de carácter internacional, tales como, la COPPAL (Conferencia Permanente de Partidos Políticos de América Latina), el Comité Anti-imperialista de los Pueblos, la ALDHU (Associación Latinoamericana de los Derechos Humanos), Contadora, etc.

Los nuevos actores internacionales juegaron un papel importante en la defensa y protección de los derechos humanos, el respeto a la auto determinación de los pueblos y en contra de la intervención de los EE.UU. en América Central. Igualmente, existieron algunos que se encontraban regionalizados, tales como, la Internacional Socialista ${ }^{8}$ y la Comunidad Económica Europea9, ambos actores se activaron en la solución por las vías pacíficas del conflicto de América Central.

Las estrategias empleadas para ganar el sostén político y diplomático fueron las siguientes: en los casos de la guerra de América Central, se explicaba que no fue un conflicto de carácter regional en strictu sensus, sino que de orden internacional, puesto que varios países intervinieron, convirtiendose automáticamente en partes involucradas, sea directa o indirectamente, por ejemplo, los EE.UU, Israel, y Sudáfrica, fueron abastecedores de armas, además de asesorar militamente a los “contras" nicaraguenses y a los gobiemos de Guatemala, El Salvador y Honduras.

A partir de finales de 1989, la URSS disminuyó el abastecimientos de armas a Nicaragua, a principios de 1990 la Unión Soviética había suspendido totalmente los envíos militares a los nicaraguenses. Sin embargo, los EE.UU continuaban apoyando militar y económicamente a los gobiernos reaccionarios de América Central.

En este mismo orden, era necesario demostrar diáfanamente que la guerra era un verdadero atentado contra la paz y a la seguridad internacional. Por esta razón, fue necesario hacer presión sobre los EE.UU y el gobierno salvadoreño para poner término a la guerra por medios pacíficos.

Los EE.UU. y sus aliados podían acoger la solución pacífica a la controversia gracias a tres factores importantes:

A- El poder y la capacidad político-militar del movimiento revolucionario.

B- Las presiones internas.

C- Las presiones diplomáticas ejercidas por la comunidad internacional.

El reconocimiento diplomático a la izquierda salvadoreña, con la Declaración Franco-Méxicana de agosto de 1981, reconoció “al FDR-FMLN de El Salvador como una fuerza política representativa, y de una importancia vital para pueder contribuir a la solución del conflicto"'(). El solo reconocimiento fue un gran instru- 
mento de presión político-dimplomático.

Por otro lado, se planificaba y coordinaba con sus representantes acreditados en otros países, la utilización de las declaraciones, comunicados y otros, emitidos por gobiernos, organismos internacionales, etc, que favorecieran al movimiento revolucionario, ya que esos momentos fueron importantes y pudieron hasta ser determinantes, y lo peor hubiera sido, dejar pasar por alto la oportunidad coyuntural que se presentó.

Una declaración o comunicado de trascendencia podía dar pie, perfectamente a quel comité planificara la realización de una gira de algunos dirigentes del movimiento revolucionario por varios países, situación propicia para promover la solidaridad, la cooperación, participar en las conferencias internacionales, consolidar, establecer nuevas relaciones políticas y diplomáticas.

Las misiones diplomáticas de alto rango (constituidas por dirigentes políticos o guerrilleros) ofrecían conferencias de prensa, participaban en coloquios, en seminarios con el objeto de informar lo que ocurrfa en ese momento en el país, en fin, denunciar las prácticas terroristas que la dictadura cometía con el amparo y patrocinio de los EE.UU.

Algunos dirigentes de alto nivel del movimiento revolucionario que cumplían tareas en el campo de las relaciones internacionales, tendían a "aburguesarse", y despreciaban no sólo a sus compatriotas que residían en el extranjero, a los compañeros nacionales del país anfitrion que realizan la solidaridad con la revolución, sino, que hasta sus mismos compañeros de militancia, obviamente cuando éstos eran de la base social.

A los dirigentes seudo-revolucionarios no les interesaba tener reuniones con la masa, sino sólo y únicamente de "alto nivel" con los dirigentes del país, porque estaban más interesados en los dólares, que en la solidaridad efectiva de la base social. Como regación de lo anterior podríamos citar, de ejemplo, al líder sudafricano Nelson Mandela, quien compaginaba las reuniones populares de solidaridad con las de alto nivel, priviligiando de esta manera ambos niveles.

Por otra parte cuando el dictador o una comitiva del gobierno oficial decidía hacer una gira por razones propagandísticas, económicas, etc, por uno o varios países, el comité preparaba una ofensiva diplomática con sus representantes, y éste con las diferentes organizaciones y partidos políticos, del país o países por el cual realizaría el periplo, con la finalidad de preparar actos de hostigamimento, piquetes, manifestaciones, etc. El comité para renforzar esta iniciativa, enviaba una misión diplomática antes que los gobiernistas empezaran la suya, con el fin de "minarles el camino".

El comité exponía a la comunidad internacional que el movimiento revolucionario luchaba por obtener, la independencia, autodeterminación, soberanía y la paz y, que su lucha era en contra la dominación imperialista y neo-colonial. Es entonces, por esta razón que se tipifica a la guerra revolucionaria en la acepción moder- 
na del término como guerra de liberación nacional. Porque los virreyes o gobernadores de antaño fueron sustituidos por gobiemos satélites, compuestos por nacionales "vende patria".

La guerra de liberación nacional tuvo aliados naturales; eran principalmente los países del Tercer Mundo que contaban con gobiernos democráticos. Se recordará que cuando la Organización de las Naciones Unidas (ONU) se formó en San Francisco en 1945, con una cincuentena de países independientes, y actualmente más de 180 la confornan en este momento, la mayoría se encontraban bajo la dominación imperialista. En día sólo el continente africano cuenta con más de cincuenta y siete países y América Latina con una treintena.

El comité, a través de sus representantes, sus misiones diplomáticas, sus dirigentes políticos y militares, instaba a las personalidades extranjeras de importancia internacional, así como a los jefes de Estado y de gobiemo, sin olvidar a los ministros de relaciones exteriores, de exponer el conflicto ante los diferentes foros intemacionales donde ellos participaban, especialmente ante la ONU, con el objeto de aislar y condenar al gobiemo contra el cual se luchaba, de igual forma para presionar a la Administración estadounidense para que suspendiera su injerencia en los asuntos internos del país en el cual se combatía.

Por lo general el conflicto regional es del interés de la comunidad internacional, porque en una guerra revolucionaria, las partes en conflicto no están fuera de las reglas y normas que regulan las relaciones internacionales. El conflicto toma interés diplomático cuando se comienza a poner en peligro los principios fundamentales sobre los que descansa el presente sistema internacional. De igual manera, cuando hay violaciones al derecho internacional, esta situación coloca en evidente peligro el actual sistema jurídico internacional, que vela por el respeto de los derechos humanos, la prohibición del genocidio y la utilización de armas químicas y bacteriológicas, etc.

\section{Actores priviligiados}

Los actores priviligiados eran los que podían brindar un aporte importante a la causa revolucionaria, jugaban un rol significativo en las relaciones internacionales, es decir, grupos de presión, personalidades y sujetos de derecho internacional, etc. Los actores internacionales se clasifican de la manera siguiente:

\section{A- Militantes}

Se refería a los actores extranjeros que tenían homólogos políticos, sindicales, religiosos, etc, en el movimiento revolucionario, se identificaban con la revolución por cuestiones de principios, especialmente por fraternidad solidaria, fueron los más activos y comprometidos con el movimiento revolucionario. 


\section{B- Humanitarios}

Eran los organismos internacionales o nacionales que ayudaban por razones de humanitarismo, principalmente para promover el respeto de los derechos inalienables del hombre y, para realizar proyectos de desarrollo con el fin de ayudar a las personas víctimas de la represión. Ellos elaboraban proyectos, algunas veces en las zonas de conflicto, no soló para ayudar economicamente a las víctimas civiles, sino para proteger la vida de los pobladores, con su presencia.

La presencia disuasiva de personas extranjeras pertenecientes a organismos de esta naturaleza, proporcionaba cierta protección a caseríos y pueblos, que fueron susceptibles de bombardeos indiscriminados. A la vez, esta presencia, podía ser empleada para otorgar protección a los locales de sindicatos, organizaciones, etc, de la misma manera para ofrecer protección a los líderes del movimiento social, para evitar su desaparición, tortura y asesinato.

\section{C- Simpatizantes}

Sin ser militantes de partidos políticos ni miembros de organismos humanitarios, los simpatizantes ayudaban al movimiento revolucionario de una manera altruísta y solidaria. Se trataba de funcionarios o miembros de organizaciones no gubernamentales, de clubes, de grupos comunitarios o de ciertas personalidades independientes, científicos, escritores, etc.; jugaban un rol clave, porque su imparcialidad le daba más relieve a la solidaridad internacional.

Los actores internacionales humanitarios, religiosos, grupos de solidaridad, etc, podían hacer cambiar la posición de sus respectivos jefes de Estado y, de sus gobiernos en relación con el movimiento revolucionario. Esto fue el caso en la guerra de Vietnam, diferentes líderes y organizaciones, hicieron llamados para realizar las grandes manifestaciones en varios países, particularmente en Europa y en EE.UU. para protestar y condenar la intervención estadounidense. En efecto, lograron cambiar no sólo la opinión pública estadounidense e internacional, sino la posición pro-imperialista que sostenf́an varios políticos, luego éstos últimos coadyuvaron también para presionar a la Administración de los EE.UU. a retirarse de Vietnam. Como último caso, podemos mencionar el conflicto de El Salvador, la presión internacional e interna impidió a los EE.UU. de intervenir directamente ese país centroaméricano como lo hicieron en Vietnam.

Otro factor que hay que tomar en cuenta en nuestro análisis es que si bien es cierto, de los resultados positivos de las presiones para lograr la abstenencia intervencionista de forma militar directa y masiva. No obstante éstas no son las causas medulares que la evitaron, sino, primordialmente el grado de desarrollo político y militar alcanzado por el movimiento revolucionario salvadoreño, lo cual fue un poder y una capacidad real de respuesta, que no existió en República Dominicana (1965), ni en Granada (1983) como tampoco la hubo en Panamá 
(1989), si los estadounidenses hubieran invadido El Salvador, probablemente hubiera sido igual o peor a la derrota que le causó el pueblo vietnamita.

Las actividades de los actores internacionales y nacionales fueron con el objeto principal de sensibilizar, y, formar opinión pública nacional e internacional en favor de la lucha revolucionaria, y contra el terrorismo de Estado y el imperialismo.

Las actividades podían ser llevadas a término de una manera directa e indirecta. Tomemos a razón de ejemplo, una actividad directa especifica y concreta, las actividades de solidaridad con el pueblo y gobiemo sandinista, dirigidas contra la "guerra no declarada" que sostenían los EE.UU. contra Nicaragua. En cuanto a las actividades indirectas, se podrían haber considerado entre otras, una marcha de paz o por el desarmamento a nivel regional o internacional, en éstas se hubiera podido incluir también la denuncia de las actividades terroristas de los EE.UU. contra los demócratas y revolucionarios que luchaban contra la opresión y la injusticia.

Por otro lado, entre las organizaciones de la juventud que más se destacaron por su solidaridad con los pueblos oprimidos que mantenían una lucha titánica contra el imperialismo, podemos citar, la Federación Mundial de la Juventud Democrática (F.M.J.D.), de orientación comunista, la Unión Internacional de Estudiantes (U.I.E), de orientación comunista, la Unión Internacional de la Juventud Socialista (I.U.S.Y.), de orientación socialista democrática, compuesta por las organizaciones de jóvenes miembros de los partidos pertenecientes a la Internacional Socialista (I.S).

En el mundo sindical, encontrabamos entre otras: la Federación Sindical Mundial (F.S.M.) de orientación comunista, la Confederación Internacional de Sindicatos Libres (C.I.S.L.), de orientación social demócrata, la Confederación Mundial del Trabajo (C.M.T.), de orientación social o demócrata cristiana" "Estas internacionales políticas creaban actitudes de cooperación, a través de contactos directos entre personalidades de países diferentes" 12 .

En Europa, existían las confederaciones de estudiantes, obreros y campesinos, que reagrupaban a las diferentes organizaciones homólogas de diferentes signos políticos e ideológicos que existían en cada país. A nivel regional, por ejemplo, se encontraban; los Círculos Juveniles de Europa (C.M.Y.C.) y la Confederación Europea de Sindicatos (C.E.S.). A nivel nacional, existían confederaciones de asociaciones homólogas, por ejemplo, el Consejo Nacional de la Juventud Sueca, la Unión Nacional de Estudiantes de Francia (U.N.E.F.), y la Federación de la Juventud Católica de Alemania Federal (F.O.C.J.E.C.).

Es necesario saber que las internacionales no fueron todas monolíticas, es decir, que sus miembros no tenían necesariamente la misma posición política en relación con los movimientos de liberación. En la Internacional Socialista (I.S.), 
existían en sus filas un número reducido de partidos miembros que se caractetizaron por sus posiciones ambiguas, reaccionarias e inconsecuentes con la luchas revolucionarias, los más destacados entre ellos fueron, el Partido Socialista de Portugal (PSP), el Partido Laborista de Israel (PLI), el Partido de Liberación Nacional de Costa Rica (PLN) y, el Partido Acción Democrática de Venezuela (AD).

En América Latina, los partidos miembros de la I.S., que habitualmente apoyaban la política exterior de los EE.UU., fueron Liberación Nacional de Costa Rica y Acción Democrática de Venezuela, entre sus acciones más célebres y a la vez sobresalientes podemos mencionar el siguiente caso.

La conferencia de la Internacional Socialista en Caracas. Del 23 al 25 de febrero de 1982, debía tener lugar en la capital de Venezuela una conferencia de partidos miembros de la Internacional Socialista, marcada por una discusión profunda sobre la situación en América Latina y del Caribe. Ahora bien el presidente de la Internacional Socialista, Willy Brandt, había invitado a esta reunión a los representantes del Frente Sandinista de Nicaragua. Pero los dos partidos socialistas, los de Venezuela y de Costa Rica, se oposieron a la presencia sandinista ${ }^{13}$.

Ellos argumentaban que los sandinistas no tenfan nada que hecer en la conferencia, por considerarlos comunistas, posición difundida por los EE.UU. avalada y defendida por todas aquellas fuerzas que como Liberación Nacional y Acción Democrática coincidían por entero con las tesis estadounidense. Razón por la cual, la conferencia de la I.S. no se efectúo en Venezuela sino que, fue realizada en República Federal de Alemania con la presencia de los sandinistas.

\section{IV. ¿ Por qué el éxito de la solidaridad ?}

La solidaridad tenía éxito, porque la lucha revolucionaria descansaba sobre los principios que inspiran las actuales relaciones internacionales entre las naciones. Ciertas instituciones internacionales velaban en efecto, por el respeto, acatamiento y la defenza de los derechos humanos, culturales, sociales, civiles, etc.

A excepción de los EE.UU. y sus acólitos, nigún país democrático defendía un movimiento armado que practicara la represión, terror, racismo, genocidio, tortura, etc. Los países y gobiernos que fueron más solidarios con los movimientos que luchaban por la democracia y la paz, fueron por lo general aquellos que protegían a su propia población, contra no importa que forma de violación de los derechos del hombre. Hubiera sido utópico haber creido que los gobiernos que tuvo El Salvador durante el conflicto armado pudieran haberse solidarizado con los pueblos oprimidos. "Esto quiere decir que la política exterior de un Estado está intimamente ligada a su política interior, pues ella no es sino, que la prolongación en otro plan"14. 
La solidaridad de los países del Tercer Mundo era por lo general, política y diplomática, hay una minoría que se destacó por su cooperación de carácter económico y militar, ante los diversos foros internacionales, porque ellos en su mayoría para devenir países habían tenido que pasar por la lucha contra el colonialismo y el imperialismo, sabían que el combate que emprendía un movimiento revolucionario en cualquier parte del orbe contra el imperialismo era también la suya, es por esta razón que su solidaridad era militante. "La epoca contemporánea se caracteriza por un florecimiento de Estados nuevos, nacidos en la mayoría del movimiento de descolonización de los años 60"15.

El grueso de los países del Tercer Mundo eran miembros del Movimiento de Países no Alineados, como medida política-diplomática para evitar caer en el juego que existía de la bipolaridad en el contexto de guerra fría, su pertenencia al Movimiento les impedía entrar a formar parte de las Alianzas y Tratados militares lidereados por las superpotencias (URSS-EE.UU.) ${ }^{16}$, con esta actitud los miembros del Movimiento no Alineado contribuyeron a que la guerra fría no se calentara, y diera paso a un holocausto termo-nuclear en donde no hubieran sobrevivido ni los perdedores ni los ganadores.

El Movimiento de Países no Alineados fue una de las organizaciones internacionales, que ofrecía una solidaridad militante a todos los movimientos de liberación, además en muchos de los casos fue la primera en reconocerlos y en otorgarles la solidaridad sin cortapisas.

En América Latina, el movimiento revolucionario salvadoreño y el primer gobierno sandinista de Nicaragua (1979-1990) además de obtener el beneficio de la solidaridad, la cooperación, y el apoyo político-diplomático de los Países No Alineados contarón también con el apoyo de varios países latinoaméricanos.

En América Latina, la cuasa sandinista logró suscitar una nueva unidad. En el momento de la guerra contra la dictadura somozista se constituyó un "vasto frente democrático-independentista, anti-imperialista y anti-intervencionista", según la expresión de Fidel Castro. Por la primera vez, se asistió a una insubordinación masiva de los países latinoaméricanos con respecto a Washington. Refusando, en la décima séptima conferencia de la Organización de Estados Américanos (O.E.A.), la proposición de los Estados Unidos de crear una "fuerza de paz", la gran mayoría de las naciones de América Latina impidió que los sandinistas no fueran frustados de su victoria en el último momento. Panamá, Costa Rica, México, Venezuela y los otros países del Pacto Andino jugaron un rol determinante para hacer fracasar esta maniobra a última hora ${ }^{17}$.

Esto se debió al hecho que, las dictaduras militares impuestas a los patriotas de los países de América Latina por los EE.UU. habían comenzado a desaparecer' ${ }^{18}$, resurgieron algunos gobiernos que trataban de recobrar la dignidad no sólo nacio- 
nal sino también continental, como el caso de Alan Garća del partido APRA del Perú (1985-1990) y de Rodrigo Borja del partido Izquierda Democrática de Ecuador (1989-1992), entre otros.

Los políticos y jefes de Estado militares habían dejado de parasitar en los gobiemos no sólo por el desprestigio que ganaron con todos sus crimines, robos al erario, sino que esencialmente, porque ya no había más que robar, dejando a los países con una gran deuda externa y en la miseria. El relevo y la herencia de la bancarrota nacional y de las heridas causadas por el odio engendrado por el militarismo, fué tomado por los partidos reformistas y populistas que trataban de conciliar el "interés nacional con los intereses del imperialismo".

\section{Notas y referencias}

1. Philippe Braillard y Mohammad Reza D., Les relations intemationales, Paris, Les Editions Ouvriéres, 1983, p.113.

2. Cfr. Claude-Albert Colliard, Instituciones de relaciones Internacionales, Madrid, Fondo de Cultura Económica, 1978, p.p.321-330.

ONU, "Capitulo VI: Arreglo pacffico de controversias", en la Carta de las Naciones Unidas, San Francisco, 26-06-1945.

3. Vide, Oscar Martínez Peñate, "Embargo a Nicaragua transgresión al derecho internacional", en Relaciones Intermacionales, San José, Movimiento Estudiantil de Relaciones Internacionales del Collegium Latinum (MERI) de la Universidad Autónoma de Centro América (UACA), No.3, 1986, p.12.

4. Jacques Lambert y Alain Gandolfi, Le système politique de l'Amérique Latine, Paris, Presses Universitaires de France, 1987, p.563.

5. Vide, Séverine Pacteau y François-Charles M., Historie des relations intemationales (1985-1987): que sais je?, Paris, Presses Universitaires de France, 1988, p.108 Ss.

6. Cvijeto Job, "Bendiciones y dificultades con plegariasrespondidas: el Mundo Nuevo y los viejos temores Il", en Poltsica Internacional, Belgrado, No.964, 5-VI-1990, p.19.

7. Léonard Dubé, Organisation et structures: autonomie et coordination, Montréal, Editions France-Amérique, 1980, p.47.

8. Hugues Portelli, L'Internationale Socialiste, Paris, Les Editions Ouvrières, 1983, p.113. André Donneur, L'Internationale Socialiste: que sais-je?. Paris. Presses Universitaires de France, 1983, p.91.

"La Internacional Socialista apoya Contadora", en Informativo El Salvador, San José, Oficina de Información del Frente Democrático Revolucionario (FDR), No.11, 15-071983, p.p.1-2.

9. Cfr. "Cita transcendental", en Prisma Latinoaméricano, Habana, Prensa Latina, No.147, noviembre 1984, p. 10.

"Comunidad Económica, Contadora y Centro América", en Opinión Popular, San José, Movimiento Nacional Revolucionario de El Salvador (MNR), No.18-19, noviembre-diciembre 1984, p.I1.

"Reencuentro Latinoaméricano", en Comercio Exterior, México,

Banco Nacional de Comercio Exterior, Vol.34, No.10, febrero 1985, p. 146.

10. FDR-FMLN, La búsqueda de la paz un esfuerzo constante, San Salvador, Centro de Comunicaciones Liberación, 1982, p.38. 
11. Vide, Jean Auger, Sindicalisme des autres, syndicats d'Europe: les internationales sindicales, Paris, Les Editions Ouvrières, 1980, p.188.

12. Pierre Gerbet, Les organisations internationales: que sais-je?, Paris, Presses Universitaires de France, 1966, p.50.

13. Branko Lazitich, "L'intemationale socialiste et la lutte pour la paix", Après la détente, un dossier de la revue Politique Intemationale, présenté par Patrick Wajsman, Paris, Hachette, 1982, p.110.

14. Tran Van Minh et al, Politique comparée du Tiers-Monde: visages du Tiers-Monde et forces politiques, Paris, Editions Moncherestien, 1980, p.6.

15. Edmon Jouve, Le Tiers-Monde dass la vie intermationale, Paris, Benger-Levrault, 1983, p.99.

16. Eugène Berg, Non alignement et nouvel ordre mondial, Paris, PUF, 1980, p.72.

17. Véronique Soulé et al, Nicaragua: le modèle sandinista, Paris, Le Sycomore, 1981, p.99.

18. Oscar Martínez Peñate, "L'OEA et les USA", en Le Devoir, Montréal, 18-11-1989, p.A-8. 